\title{
First Report of Resistance to Pyraclostrobin, Boscalid, and Thiophanate-methyl in Colletotrichum gloeosporioides from Blueberry in Georgia
}

\author{
Md Emran Ali, ${ }^{\dagger}$ Owen Hudson, Will H. Hemphill, Timothy B. Brenneman, and Jonathan E. Oliver \\ Department of Plant Pathology, University of Georgia, Tifton, GA 31793
}

Accepted for publication 7 November 2019.

Keywords: Fungicide resistance, Colletotrichum gloeosporioides, blueberry, small fruit

Colletotrichum gloeosporioides causes anthracnose fruit rot and leaf spot on blueberries. Anthracnose fruit rot has been reported in all major blueberry growing regions in the United States (Milholland 2017). This can occur either preharvest, on developing fruit in the field, or postharvest, on stored matured fruit. In the field, it causes berry softening and production of orange spore masses on fruit. Affected fruit drop prematurely from the plant. Further loss occurs through postharvest infection in storage bins. An article published by Polashock et al. (2007) claimed that losses due to anthracnose preharvest are typically 3 to $5 \%$, and postharvest losses can reach up to $100 \%$. For controlling anthracnose, blueberry growers mostly rely on pre- and postharvest fungicide applications in addition to orchard sanitation. Single-site fungicides including quinone outside inhibitors (QoIs), such as pyraclostrobin and azoxystrobin, as well as fungicides containing the succinate dehydrogenase inhibitor (SDHI) boscalid are used frequently to control anthracnose rots and other diseases on blueberry; however, development of fungicide resistance is a real risk because a limited number of fungicides are now available for blueberry disease management.

In 2019, extension personnel reported a failure of ripe rot control in commercial blueberry fields in Pierce County, Georgia, despite multiple applications of fungicides between bloom and harvest. From two of these commercial fields, three isolates of C. gloeosporioides were cultured from blueberry fruit collected from southern highbush blueberry cultivar 'Farthing'. These fields had received multiple applications of QoI fungicides and combinations including azoxystrobin and pyraclostrobin plus boscalid during the 2019 growing season, as well as in previous seasons. Some applications included tank mixes with the multisite contact fungicide captan; however, the majority of applications consisted of a QoI (or combination) product without captan. Less frequently, other fungicides from different modes of action had been applied, including cyprodinil plus fludioxonil combinations. The pathogen was isolated on acidified quarter-strength potato dextrose agar, and the identity of the isolates was confirmed using morphological

\footnotetext{
${ }^{\dagger}$ Corresponding author: M. E. Ali; emran.ali@uga.edu
}

Funding: This work was funded by Georgia Commodity Commission for Blueberry (grant no. FP00016535).

The author(s) declare no conflict of interest.

(C) 2019 The American Phytopathological Society characteristics and sequencing of the ITS1 and ITS4 fragment (White et al. 1990). The ITS sequence result from two isolates (one from each field) (GenBank accession numbers MN565958 and MN565960) had $100 \%$ identity to a $C$. gloeosporioides sequence (GenBank accession number KC010547), and the sequence from the other isolate (GenBank accession number MN565959) had $100 \%$ identity to another C. gloeosporioides sequence (GenBank accession number HQ645082). Fungicide sensitivity tests were conducted on three isolates as well as a known QoI-sensitive control isolate of $C$. gloeosporioides using a mycelial growth inhibition assay as described previously Ali et al. (2018). A total of nine fungicides were evaluated to determine the sensitivity of these C. gloeosporioides isolates. The fungicides included pyraclostrobin at $100 \mu \mathrm{g} / \mathrm{ml}$ (Cabrio, BASF, Research Triangle Park, NC),

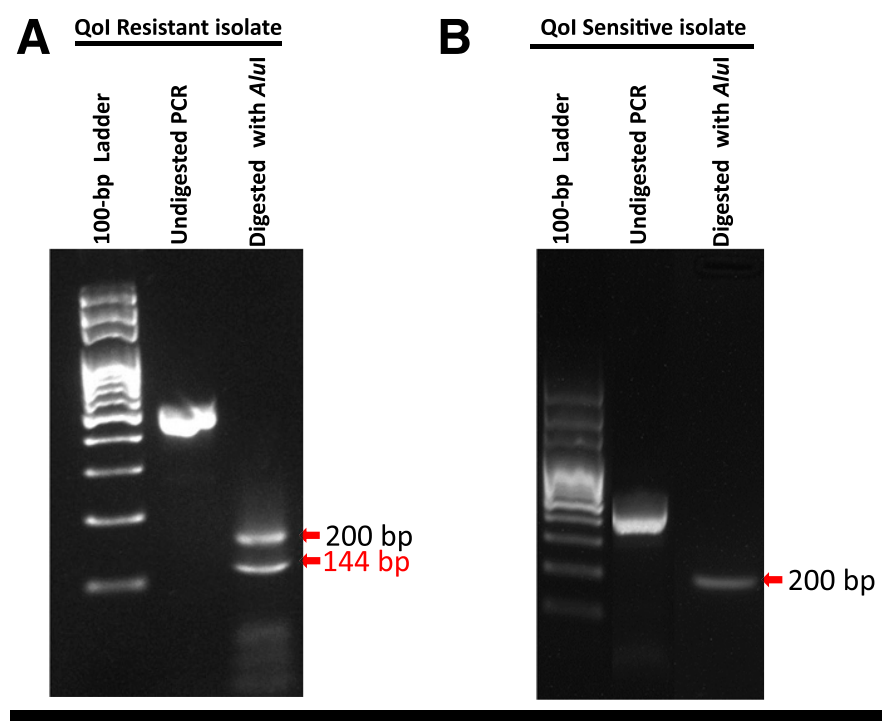

FIGURE 1

Detection of the G143A mutation in the cytochrome $b$ (cytb) gene using the polymerase chain reaction restriction fragment length polymorphism (PCRRFLP) assay for Colletotrichum gloeosporioides from blueberry. Amplified PCR products using cytb-specific primers were digested with Alul. A, Quinone outside inhibitor (Qol)-resistant isolate displaying two bands after PCR-RFLP analysis was confirmed to have the G143A mutation in the cytb gene. B, Qolsensitive isolate displaying one band after PCR-RFLP analysis. Undigested $P C R$ products of resistant and sensitive isolates are also shown. 
thiophanate-methyl at $100 \mu \mathrm{g} / \mathrm{ml}$ (Topsin-M, UPI, King of Prussia, PA), fenhexamid at $50 \mu \mathrm{g} / \mathrm{ml}$ (Elevate, Arysta Life Sciences, Cary, $\mathrm{NC}$ ), fludioxonil at $0.50 \mu \mathrm{g} / \mathrm{ml}$ (Scholar, Syngenta Crop Protection, Research Triangle Park, NC), iprodione at $15 \mu \mathrm{g} / \mathrm{ml}$ (Rovral, Bayer Crop Science, Greensboro, NC), cyprodinil at $4 \mu \mathrm{g} / \mathrm{ml}$ (Vanguard, Syngenta Crop Protection), boscalid at $50 \mu \mathrm{g} / \mathrm{ml}$ (Endura, BASF), penthiopyrad at $5 \mu \mathrm{g} / \mathrm{ml}$ (Fontelis, DuPont Crop Protection, Willington, DE), and fluopyram at $10 \mu \mathrm{g} / \mathrm{ml}$ (Luna Privilege, Bayer CropScience). The discriminatory doses for these fungicides were adapted from Amiri et al. (2014), except boscalid, which was developed in our study. Sensitivities to pyraclostrobin, thiophanatemethyl, fenhexamid, fludioxonil, cyprodinil, and iprodione were assessed on $1 \%$ malt extract agar (10 g of malt extract and $15 \mathrm{~g}$ of agar), and boscalid, penthiopyrad, and fluopyram was evaluated on yeast Bacto acetate agar (10 g of yeast extract, $10 \mathrm{~g}$ of Bacto peptone, $20 \mathrm{~g}$ of sodium acetate, and $15 \mathrm{~g}$ of agar) (Stammler and Speakman 2006). Two mycelial plugs taken from the edge of a growing 10-day-old colony of each isolate were transferred upside down at the centers of fungicide-amended plates and nonamended control plates. Plates were incubated for 5 days at $22^{\circ} \mathrm{C}$ before measuring the radial growth in two perpendicular directions and determining fungicide sensitivity. Four plates were used for each fungicide, and sensitivity tests were repeated twice. The growth of the sensitive isolate was 95 to $100 \%$ inhibited by the discriminatory doses for these fungicides, but resistant isolates were slightly $(\leq 5 \%)$ or not at all inhibited by the discriminatory doses. Similarly, all three isolates were not inhibited by the discriminatory doses of thiophanate-methyl, the QoI fungicide pyraclostrobin, and to the SDHI fungicide boscalid. Thus, the three isolates from blueberry were considered resistant to these three fungicides.

It is widely reported that resistance to QoIs has been associated with the presence of amino acid substitution G143A in the cytochrome $b$ gene (Forcelini et al. 2018). For further confirmation of the pyraclostrobin resistance phenotype, we examined all three resistant isolates for the presence of the G143A substitution using the polymerase chain reaction (PCR) restriction fragment length polymorphism assay as described by Forcelini et al. (2018). Our results confirmed the presence of the G143A mutation in all three $C$. gloeosporioides isolates from blueberry (Fig. 1). These results were consistent with the previously reported relation between the QoI resistance phenotype and G143A in the cytochrome $b$ gene. The amplified PCR products using cytochrome $b$ primers were also sequenced and subjected to BLAST analysis, which confirmed the presence of the G143A mutation. To our knowledge, this is the first report of resistance to pyraclostrobin, thiophanate-methyl, and boscalid in C. gloeosporioides from blueberry in Georgia. These findings suggest that continuous monitoring of fungicide resistance in Georgia blueberry plantings is necessary to avoid the unwarranted application of single-site fungicides that might be ineffective.

\section{Literature Cited}

Ali, E. M., Pandit, L. K., Mulvaney, K. A., and Amiri, A. 2018. Sensitivity of Phacidiopycnis spp. isolates from pome fruit to six pre- and postharvest fungicides. Plant Dis. 102:533-539.

Amiri, A., Zuniga, A. I., Mertely, J., and Peres, N. A. 2014. First report on resistance to pyraclostrobin, thiophanate-methyl and boscalid in Botrytis cinerea from eucalyptus seedlings in Florida greenhouses. Plant Dis. 98:851.

Forcelini, B. B., Rebello, C. S., Wang, N. Y., and Peres, N. A. 2018. Fitness, competitive ability, and mutation stability of isolates of Colletotrichum acutatum from strawberry resistant to QoI fungicides. Phytopathology 108: 462-468.

Milholland, R. D. 2017. Anthracnose fruit rot. Pages 10-12 in: Compendium of Blueberry, Cranberry, and Ligonberry Diseases and Pests, 2nd Edition. J. J. Polashock, F. L. Caruso, A. L. Averill, and A. C. Schilder, eds. APS Press, St. Paul, MN.

Polashock, J. J., Saftner, R. A., and Kramer, M. 2007. Postharvest highbush blueberry fruit antimicrobial volatile profiles in relation to anthracnose fruit rot resistance. J. Am. Soc. Hortic. Sci. 132:859-868.

Stammler, G., and Speakman, J. 2006. Microtiter method to test the sensitivity of Botrytis cinerea to boscalid. J. Phytopathol. 154:508-510.

White, T. J., Bruns, T., Lee, S., and Taylor, J. W. 1990. Amplification and direct sequencing of fungal ribosomal RNA genes for phylogenetics. Pages 315-322 in: PCR Protocols: A Guide to Methods and Applications. M. A. Innis, D. H. Gelfand, J. J. Sninsky, and T. J. White, eds. Academic Press, San Diego, CA. 